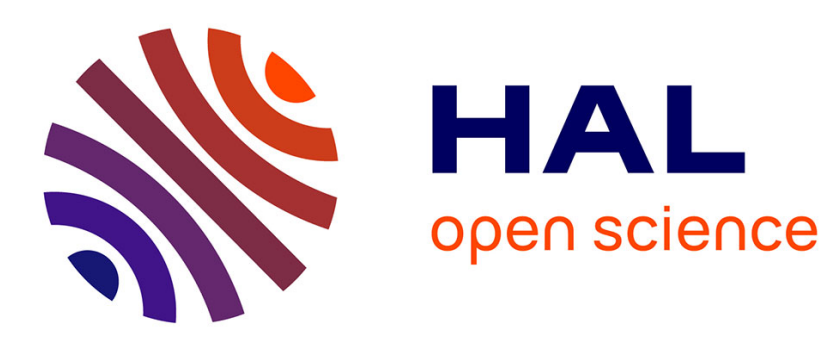

\title{
Thermal stability of titanium hydride thin films
}

\author{
H. Chatbi, M. Vergnat, G. Marchal
}

\section{To cite this version:}

H. Chatbi, M. Vergnat, G. Marchal. Thermal stability of titanium hydride thin films. Applied Physics Letters, 1994, 64 (10), pp.1210-1211. 10.1063/1.111950 . hal-02113411

\section{HAL Id: hal-02113411 https://hal.science/hal-02113411}

Submitted on 28 Apr 2019

HAL is a multi-disciplinary open access archive for the deposit and dissemination of scientific research documents, whether they are published or not. The documents may come from teaching and research institutions in France or abroad, or from public or private research centers.
L'archive ouverte pluridisciplinaire HAL, est destinée au dépôt et à la diffusion de documents scientifiques de niveau recherche, publiés ou non, émanant des établissements d'enseignement et de recherche français ou étrangers, des laboratoires publics ou privés. 


\title{
Thermal stability of titanium hydride thin films
}

\author{
H. Chatbi, M. Vergnat, and G. Marchal \\ Laboratoire de Métallurgie Physique et Sciences des Matériaux (U.R.A. au C.N.R.S. $n^{\circ}$ 155) \\ Université de Nancy I, B. P. 239, 54506 Vandouvre-les-Nancy Cedex, France
}

(Received 22 October 1993; accepted for publication 7 December 1993)

The thermal stability of titanium hydride thin films prepared by reactive evaporation is reported. The release of hydrogen is monitored by the effusion method. The gas evolution spectrum shows two peaks corresponding to the hydrogen effusion from the titanium hydride phase and to the crystallographic transformation from fcc to hcp structure, respectively.

Neutron supermirrors are multilayers of nickel and tilanium. The reflectivity of this system can be still improved if pure titanium is replaced by titanium saturated with hydrogen, which would give an increased difference between the two indices of refraction and would allow one to diminish the number of layers needed. ${ }^{1}$ It is then necessary to introduce hydrogen in titanium and to study its thermal stability.

This letter shows that it is possible to prepare hydrogenated titanium thin films by reactive evaporation. Their thermal stability is reported. The structure of the films is characterized by electron and $x$-ray diffraction. The release of hydrogen is monitored by the effusion method, a technique we used previously in the study of hydrogenated amorphous semiconductors. ${ }^{2,3}$

Titanium was evaporated from an electron beam gun in a molecular hydrogen atmosphere onto substrates maintained at room temperature. The deposition rate $(1 \AA / s)$ was monitored and controlled with a quartz microbalance system. The hydrogen flow was regulated by maintaining the total pressure in the evaporation chamber at $10^{-4}$ Torr. Transmission electron microscopy was performed at room temperature on 200-Å-thick samples deposited on grids covered with carbon. X-ray diffraction and effusion experiments were carried out on $1000-\AA \AA$-thick samples deposited on float glass substrates. X-ray measurements were performed with the $K_{\alpha}$ radiation of cobalt $(\lambda=1.789 \AA)$. For gas evolution experiments, deuterated films were used to suppress background effects due to adsorbed water. Then, the films were inserted into a quartz tube evacuated by an ionic pump and were heated at a constant rate $\left(15^{\circ} \mathrm{C} / \mathrm{min}\right)$ up to $750^{\circ} \mathrm{C}$. The deuterium partial pressure was monitored by means of a quadrupolar mass analyzer. At a constant pumping speed, it is directly proportional to the deuterium evolution rate. The $\mathrm{D}_{2}$ partial pressure versus temperature was stored in a computer system to allow numerical analysis of the effusion spectra. Although $D_{2}$ was used in place of $\mathrm{H}_{2}$, the generic term hydrogen will be used in subsequent discussions.

A typical evolution spectrum, showing the hydrogen evolution rate, that is, the number of hydrogen atoms released per unit film volume per unit time against temperature, is represented in Fig. 1. Two peaks can be observed. The first peak has a low intensity and is very broad since it spreads between 200 and $400^{\circ} \mathrm{C}$, then a second peak, intense and very narrow, appears at $405^{\circ} \mathrm{C}$. In fact, if we take account of the areas of these peaks, the first contains about as much hydrogen as the second.
The electron and $x$-ray diffraction patterns of these films as prepared and annealed at 350 and $450^{\circ} \mathrm{C}$ are represented in Figs. 2 and 3, respectively. The structure of the films as prepared and annealed at $350^{\circ} \mathrm{C}$ is identified as the fcc $\mathrm{CaF}_{2}$ structure of titanium hydride. ${ }^{4}$ In the $\mathrm{x}$-ray pattern, the only intense peak is the (111) reflection, as expected from the Joint Committee for Powder Diffraction Standard file. Because of the small thickness of the sample, the other peaks are very weak. On the contrary, all the reflections expected for a fcc structure are observed in the electron diffraction pattern. The films annealed at $450{ }^{\circ} \mathrm{C}$ present the diffraction pattern of the titanium hcp phase. ${ }^{5}$ The $\mathrm{x}$-ray pattern shows an intense (011) reflection with a lower (002) reflection. The $(010)$ and $(110)$ lines are hardly visible and the (012) line is absent. On the other hand, the electronic pattern again displays all the reflections expected for a hcp structure. This transformation from a $\mathrm{IiH}_{2}$ structure to hcp 'li is due to the above-mentioned hydrogen effusion. This temperature is in agreement with the value obtained by Yanagida et al. ${ }^{6}$ who observed the transformation of ultrafine particles of $\mathrm{TiH}_{2}$ in titanium after a heat treatment at $400{ }^{\circ} \mathrm{C}$ for $1 \mathrm{~min}$ at a pressure of $10^{-6}$ Torr.

When titanium hydride films are heated, effusion occurs, which can be analyzed in terms of the three potential ratelimiting steps: detrapping of hydrogen from bound sites in the bulk, diffusion of hydrogen in the bulk solid, and desorption from the surface. In the case of titanium, the process is complicated by the structural change from a fec hydrogenrich $\mathrm{TiH}_{2}$ phase to a hep Ti phase with a low hydrogen solubility. It can therefore be thought that hydrogen contained in

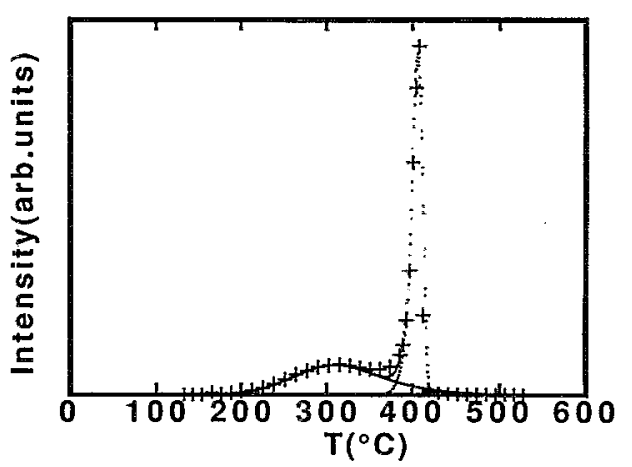

FIG. 1. Thermal effusion spectrum of a titanium hydride thin film. The experimental points are represented by the symbol + . The dotted lines represent the simulated individual and total release rate curves. 


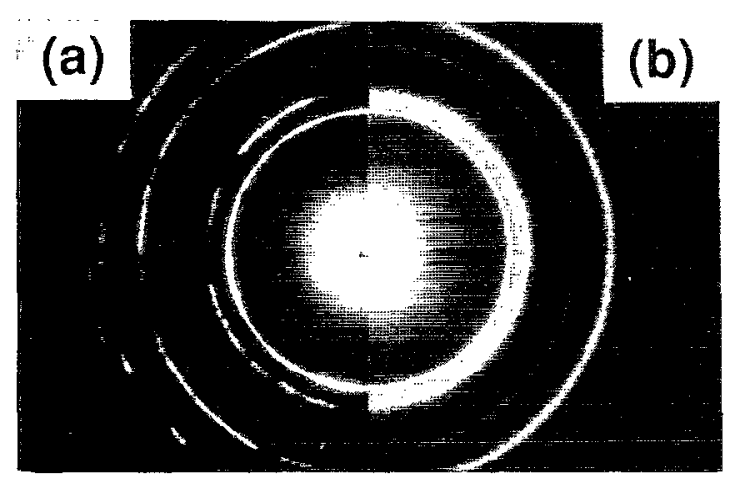

FIG. 2. Electron diffraction patterns of a titanium hydride thin film as prepared or annealed at $350^{\circ} \mathrm{C}$ (a) and annealed at $450^{\circ} \mathrm{C}$ (b).

the hcp phase after the crystallographic transformation will exit very fast from this phase since its hydrogen solubility is low. This transformation corresponds to the second very narrow peak, which is comparable in width $\left(20^{\circ} \mathrm{C}\right)$ with crystallization peaks observed in thermal desorption ${ }^{7}$ or in differential scanning calorimetry experiments. The first peak, at lower temperatures, corresponds to the classical effusion phenomenon in the $\mathrm{TiH}_{2}$ phase.

An easy way to determine whether the evolution rate is diffusion limited or not is the measurement of the thickness dependence. If diffusion limits the evolution rate, the rising diffusion length with increasing film thickness will result in a shift of the effusion peak to higher temperatures. Such a shift was not observed between films with thicknesses of 1000 and $3000 \AA$. Also, although it is difficult to precisely determine the rate-limiting step between detrapping from bound sites in the bulk and desorption from the surface, we tried to determine the kinetic parameters of the decomposition of $\mathrm{TiH}_{2}$. The kinetics of the release of the dissolved hydrogen was analyzed using the Eyring theory of absolute rate processes. ${ }^{8}$ This theory assumes that the hydrogen atom must overcome a free energy barrier $\Delta G$ in order to be evolved and the frequency at which the barrier is confronted is approximated by the factor $k T / h$, where $k$ and $h$ are the Boltzmann and Planck constants, respectively, and $T$ is the absolute temperature. Therefore, the effusion rate $R$ follows the equation

$$
R=\frac{d\left(c / c_{0}\right)}{d t}=\left(\frac{k T}{h}\right)\left(1-\frac{c}{c_{0}}\right)^{n} \exp \left(\frac{\Delta S}{k}\right) \exp \left(-\frac{\Delta H}{k T}\right)
$$

with $c_{0}$ and $c$ the original and evolved hydrogen concentrations and $n$ the order of the reaction. The free energy of desorption $\Delta G$ is equal to $\Delta H-T \Delta S$ where $\Delta H$ is the enthalpy and $\Delta S$ is the entropy of reaction. The experimental shape of the effusion curve determines the order $n$ of the kinetics.

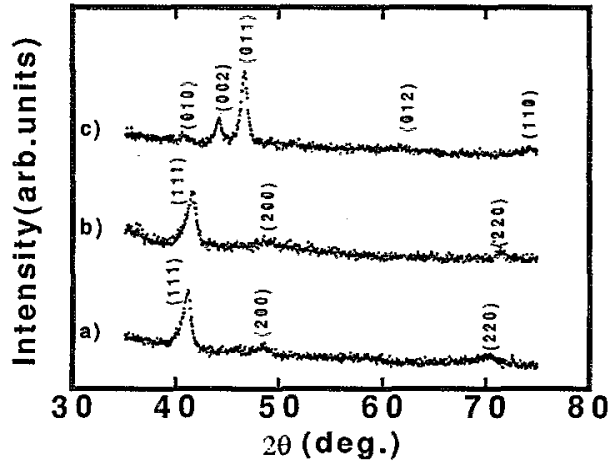

FIG. 3. X-ray diffraction patterns of a titanium hydride thin film as prepared (a) and annealed at $350^{\circ} \mathrm{C}$ (b) and $450^{\circ} \mathrm{C}$ (c).

Figure 1 shows the deconvoluted peaks and the total release rate, which is in the best agreement with the experimental curve. The fit was obtained with a second-order kinetics for the broad first peak and a first-order kinetics for the narrow second peak. The parameters of the fit are $\Delta H=0.8$ $\mathrm{eV}$ and $\Delta S=-1.7 \times 10^{-3} \mathrm{eV} \mathrm{K}^{-1}$ for the first peak and $\Delta H=6.0 \mathrm{eV}$ and $\Delta S=5.9 \times 10^{-3} \mathrm{eV} \mathrm{K}^{-1}$ for the second peak, which corresponds to $\Delta G$ values of 1.8 and $2.0 \mathrm{eV}$, respectively.

In conclusion, we showed that the evaporation of titanium in a pressure $P_{\mathrm{H}_{2}}=10^{-4}$ Torr of molecular hydrogen allows one to obtain titanium hydride thin films with the fcc structure. Electron and $x$-ray diffraction indicate that titanium hydride transforms in the hcp titanium phase at $405^{\circ} \mathrm{C}$. Effusion experiments show that the release of hydrogen begins as soon as $200^{\circ} \mathrm{C}$. The effusion spectrum can be deconvoluted in two peaks. The first one is a low-intensity and broad peak with a maximum at $310^{\circ} \mathrm{C}$. It corresponds to the effusion from the titanium hydride phase with a $\Delta G$ value of $1.8 \mathrm{eV}$. The second one at $405^{\circ} \mathrm{C}$ is an intense and narrow peak which corresponds to the crystallographic transformation with a $\Delta G$ value of $2.0 \mathrm{eV}$.

${ }^{1}$ M. Maaza, Z. Jiang, F. Samuel, B. Farnoux, and B. Vidal, J. Appl. Crystallogr. 25, 789 (1992).

${ }^{2}$ S. Houssaini, M. Vergnat, A. Bruson, G. Marchal, and C. Vettier, J. Appl. Phys. 73, 483 (1993).

${ }^{3}$ S. Houssaïni, M. Vergnat, A. Bruson, G. Marchal, Ph. Mangin, and C. Vettier, Appl. Phys. Lett. 63, 1 (1993).

${ }^{4}$ JCPDS file No. 25-982.

${ }^{5}$ JCPDS file No. 5-0682.

${ }^{6}$ A. Yamigida, S. Yatsuya, and K. Mihama, Jpn. J. Appl. Phys. 26, L25 (1987).

${ }^{7}$ G. J. van der Kolk, T. Minemura, A. van Veen, and K. R. Bijkerk, Vacuum 40, 257 (1990).

${ }^{8}$ S. Glasstone, K. J. Laidler, and H. Eyring, The Theory of Rate Processes (McGraw-Hill, New York, 1941). 